\title{
Corrigendum to "Loss of SNHG4 Attenuated Spinal Nerve Ligation-Triggered Neuropathic Pain through Sponging miR-423- 5p"
}

\author{
Xia Pan, Cheng Shen, Yayi Huang, Long Wang ${ }^{D}$, and Zhongyuan Xia \\ Department of Anesthesia, Renmin Hospital of Wuhan University, Wuhan Hubei, China \\ Correspondence should be addressed to Zhongyuan Xia; happyheropx@aliyun.com \\ Received 5 October 2020; Accepted 5 October 2020; Published 17 October 2020
}

Copyright ( 2020 Xia Pan et al. This is an open access article distributed under the Creative Commons Attribution License, which permits unrestricted use, distribution, and reproduction in any medium, provided the original work is properly cited.

In the article titled "Loss of SNHG4 Attenuated Spinal Nerve Ligation-Triggered Neuropathic Pain through Sponging miR-423-5p" [1], the last sentence in Results (Section 3.8) contains an error, where the text reading "In addition, IL-6, IL-12, and TNF- $\alpha$ protein expression was restrained by the loss of miR-423-5p whereas IL-10 was elevated by miR423-5p inhibition (Figure 8(b)), which was totally reverted by the knockdown of SNHG4." should be corrected to "In addition, IL-6, IL-12, and TNF- $\alpha$ protein expression was induced by the loss of miR-423-5p whereas IL-10 was reduced by miR-423-5p inhibition (Figure 8(b)), which was totally reverted by the knockdown of SNHG4."

\section{References}

[1] X. Pan, S. Cheng, Y. Huang, L. Wang, and Z. Xia, "Loss of SNHG4 attenuated spinal nerve ligation-triggered neuropathic pain through sponging miR-423-5p," Mediators of Inflammation, vol. 2020, Article ID 2094948, 9 pages, 2020. 